\title{
SOCIEDADE DIGITAL E OS NOVOS RUMOS DO DIREITO SUCESSÓRIO
}

\author{
Cristiano Colombo $^{1}$
}

\section{INTRODUÇÃO}

A evolução do processo comunicacional, partindo da oralidade à era digital, estabeleceu novos desafios na construção da hodierna sociedade, exigindo sério debruçar-se pela ciência jurídica. À luz da interdisciplinaridade, a História e a Sociologia permeiam o trilhar deste estudo, a fim de enxergar o futuro do direito sucessório.

Questões como: O que fazer com as informações, os arquivos, as fotografias, quando os usuários morrem?
Como sopesar o interesse privado e o interesse coletivo? Como os direitos de personalidade, inclusive o direito de privacidade, poderão contribuir para este estudo?

Dividir-se-á o presente estudo em dois capítulos: o primeiro, em que se buscará descortinar aspectos históricos, bem o atual estágio da sociedade digital; no segundo capítulo, estudar-se-á a história do direito da sucessão, e, ao final, buscar-se-á trazer propostas acerca dos próximos passos a serem perseguidos, harmonizando a sociedade digital ao direito sucessório.

1 Doutor em Direito pela Universidade Federal do Rio Grande do Sul (UFRGS). Mestre em Direito pela Universidade Federal do Rio Grande do Sul (UFRGS). Bacharel em Ciências Jurídicas e Sociais pela Pontifícia Universidade Católica do Rio Grande do Sul (PUCRS), 1999; e em Ciências Contábeis pela Universidade Federal do Rio Grande do Sul (UFRGS), 2004. Especialista em Direito Tributário pelo Instituto Brasileiro de Estudos Tributários (IBET). Professor da Faculdade de Direito da Instituição Educacional São Judas Tadeu, bem como no Curso Verbo Jurídico. 
Nesse sentido, o presente tema, que aproxima a tecnologia da morte, representa o momento de sedimentação do estudo histórico e sociológico, no rumo de uma lege ferenda.

\section{DA SOCIEDADE DIGITAL}

\subsection{Da história à sociologia: $\mathrm{a}$ construção da sociedade digital}

Para a hodierna intelecção da Ciência Jurídica, é mister valer-se de um olhar interdisciplinar, ou seja, ultrapassar o horizonte teórico ${ }^{2}$ delineado somente por uma área do saber, apropriando-se de seus mais variados campos. $^{3}$ É debruçar-se sobre a História e a Sociologia, reconhecendo a primeira como aquela que diz respeito ao passado e a segunda que se concentra nas ações do presente. ${ }^{4}$

A análise desprovida de seu viés histórico deságua, desafortunadamente, na "perda da dimensão sapiencial do direito", como acentuou Grossi: ${ }^{5}$
Acredito piamente - e escrevi muitas vezes nos últimos tempos, tornando-me quase monótono - que um dos papéis, e certamente não o último, do historiador do direito junto ao operador do direito positivo seja o de servir como sua consciência crítica, revelando como complexo o que na sua visão unilinear poderia parecer simples, rompendo suas convicções acríticas, relativizando certezas consideradas absolutas, insinuando dúvidas sobre lugares comuns recebidos sem uma adequação cultural. [...] O direito moderno está intimamente vinculado ao poder político como comando de um superior a um inferior - de cima para baixo -, visão imperativista que o identifica em uma norma, ou seja, em uma regra respeitável e autoritária; essa visão, consolidada, mesmo recentemente pelo furor da influência kelseniana, tem um custo que, na nossa opinião, é altíssimo: a perda da dimensão sapiencial do direito.

2 FOUCAULT, Michel. A ordem do discurso. Aula inaugural no Collège de France, pronunciada em dezembro de 1970. Trad.: Laura Fraga de Almeida Sampaio. São Paulo: Edições Loyola, 2012.

3 ARAÚJO, Inês Lacerda. Formação discursiva como conceito chave para a arqueogenealogia de Foucault. Revista Aulas, Campinas, n. 3, p. 1- 24, dez. 2006/mar. 2007.

4 BAUMAN, Zygmunt; MAY, Tim. Aprendendo a pensar com a sociologia. Trad.: Alexandre Werneck. Rio de Janeiro: Zahar, 2010.

5 GROSSI, Paolo. Mitologias Jurídicas da Modernidade. Florianópolis: Boiteux, 2007. p. 13-15. 
Nesse sentido, afastando-se de uma visão meramente legalista, é que se passa a estudar a evolução histórica-social da humanidade em direção à sociedade digital, para, a partir daí, construir o discurso jurídico, resgatando:

O caráter ôntico do direito como fisiologia da sociedade, a ser descoberto, lido na realidade cósmica e social e traduzido em regras. [...] liberando os fermentos atuais da estática daquilo que é vigente e estimulando o caminho para a construção do futuro. ${ }^{6}$

Observa Azambuja ${ }^{7}$ que a sociedade dos insetos vale-se de uma interação química para estabelecer laços interrelacionais, o que se denomina de "trofolaxe", enquanto o ser humano vale-se da linguagem, ou seja, a "trofolaxe social" humana. No transcurso dos tempos, a linguagem tomou diferentes formas. Mais remotamente, pautava-se pela oralidade, sem a intervenção da escrita. ${ }^{8}$ Acentua Azambuja: “'Assim, em tais sociedades toda a produção e transmissão do conhecimento, a organização da memória e inteligência coletiva e dos valores ancestrais dependiam quase que exclusivamente da oralidade”. Inclusive, mesmo na antiguidade clássica, em uma época de transição, existiam grandes defensores da comunicação oral, podendo-se relacionar entre eles o filósofo grego Sócrates, que se negou a escrever os seus estudos, tendo suas lições chegados até os dias de hoje pelas mãos de Platão. ${ }^{10}$

Nem os ideogramas, tampouco os hieróglifos, foram tão importantes para o fenômeno da "destribalização" da comunicação, em matéria escrita, como o alfabeto fonético. ${ }^{11}$ Os desenhos eram compreendidos no âmbito

6 Ibidem, p. 25.

7 AZAMBUJA, Celso Candido de. Psiquismo Digital Sociedade, cultura e subjetividade na era da comunicação digital. Nova Petrópolis: Nova Harmonia, 2012.

8 Nas palavras do autor: "Socrates stood on the border between that oral world and the visual and literate culture. But he wrote nothing. The Middle Ages regarded Plato as the mere scribes or amanuensis of Socrates" (MACLUHAN, Marshall. The Gutenberg Galaxy. The making of Typographic Man. Toronto: Toronto University Press, 2011. p. 23).

9 AZAMBUJA, op. cit., p. 435.

10 Nas palavras do autor: "Socrates stood on the border between that oral world and the visual and literate culture. But he wrote nothing. The Middle Ages regarded Plato as the mere scribes or amanuensis of Socrates" (MACLUHAN, op. cit., p. 23).

11 Nas palavras do autor: "No pictographic or ideogrammic or hieroglyphic mode of writing has the detribalizing power of the phonetic alphabet” (Ibidem, p. 22). 
dos pequenos grupos, enquanto o alfabeto fonético venceu as fronteiras, alastrando-se pelo mundo. Na lição de Azambuja:12 "A invenção da escrita dá à memória e ao pensamento humano um novo suporte físico, além dos recursos da oralidade".

No século XV, com a disseminação da imprensa, de "modo massivo e dominante”, ${ }^{13}$ opera-se a denominada "Galáxia de Gutenberg”, estabelecendo a grande metamorfose. ${ }^{14}$ A invenção da tipografia trouxe uma emergente tecnologia mecânica com a escrita impressa, ${ }^{15}$ modificando, mais uma vez, o comportamento social. O conhecimento se expande para localidades distantes, para os tradicionais centros de estudo e pesquisa. ${ }^{16} \mathrm{O}$ livro e o jornal passam a ser as "interfaces privilegiadas de comunicação”. ${ }^{17}$

Outro elemento importante para difusão do conhecimento foi o desenvolvimento tecnológico em matéria de meios de transportes, o que, sem dúvida, influenciou o meio social:
Nos tempos (não tão antigos, para falar a verdade) em que eram os pés humanos ou as patas de cavalos os únicos equipamentos de viagem, a resposta à pergunta "O quão distante é daqui a vila seguinte?" seria "Se partir agora, estará lá por volta do meio-dia"; ou "Você não chegará antes do crepúsculo. É melhor pernoitar na pensão". [...] A distância transformou-se, então, em uma questão de meio de transporte a ser usado, que não era sempre o mesmo e dependia de ter recursos para viajar de trem, ônibus, automóvel e avião. [...] Podemos falar que, durante a maior parte da história da humanidade, não havia muito a distinguir entre transporte e comunicação. ${ }^{18}$

Nesse sentido, Bauman ${ }^{19}$ identifica o surgimento da era do "software", com a invenção do rádio e do telégrafo:

Contudo, em paralelo a essas invenções, germinava uma nova era de "software", com descobertas como o telégrafo e o rádio - neles encontramos os meios de transmitir informação pura a longas distâncias sem

12 AZAMBUJA, op. cit., p. 268.

13 Ibidem.

14 MACLUHAN, op. cit.

15 Ibidem.

16 AZAMBUJA, op. cit..

17 Ibidem, p. 499.

18 BAUMAN, Zygmunt; MAY, Tim. Aprendendo a pensar com a sociologia. Trad.: Alexandre Werneck. Rio de Janeiro: Zahar, 2010. p. 176-177.

19 Ibidem, p. 176-177. 
necessidade de uma pessoa ou qualquer outro corpo físico mover-se de um lugar para outro.

\section{A revolução tecnológica existen-} te, em matéria de transporte de informação, diminuindo as distâncias e propulsando o deslocamento, de igual forma representa um novo cenário:

Enquanto um jornal impresso deveria ser entregue um a um, ser transportado de casa em casa, de cidade em cidade, de país a país, de mão em mão, o rádio vai permitir um deslocamento, em tempo real, da informação e sua possibilidade de transmissão e consumo instantaneamente. ${ }^{20}$

Lentonturier, ${ }^{21}$ por sua vez, referindo-se às "galáxias", sinaliza a denominada "Galáxia de Marconi”, diante da utilização do rádio como meio de comunicação que acabou por conformar a tribo mundial:
Dans le développement du processus de communication, on peut distinguer trois étapes: le stade primitif de la société sans écriture, dans lequel lusage de la parole fait prédominer l'ouie; la "galaxie Gutenberg”, où l'imprimerie multiplie les informations visuelles, mais parcellise linformation et la nature humaine (ce qui entraîne le travail à la chaîne, le nationalisme en politique, etc.; la "galaxie Marconi" ou ère électronique, qui propose un message simplifié mais global et reconstitue la famille humaine en une seule tribu mondiale.

No tocante à sociedade digital, estágio atual do desenvolvimento humano, todos são "atores individuais" e participantes de uma "rede de interdependência”, ${ }^{22}$ sendo o próprio objeto do estudo sociológico.

Dessa forma, cresce a importância da sociologia, na medida em que "pensa de forma relacional”, como

20 AZAMBuJA, Celso Candido de. Psiquismo Digital Sociedade, cultura e subjetividade na era da comunicação digital. Nova Petrópolis: Editora Nova Harmonia, 2012. p. 511.

21 Tradução livre do autor: "No desenvolvimento do processo de comunicação, podese distinguir três etapas: o estado primitivo da sociedade sem escrita, na qual o costume da palavra faz predominar a oralidade; a "Galáxia de Gutenberg”, onde a imprensa multiplicou as informações visuais, mas parcelou a informação e a natureza humana (este que treinou o trabalho em canais, o nacionalismo em política, etc.); a "Galáxia de Marconi" ou era eletrônica, que propõe uma mensagem simplificada, mas global, e reconstituiu a família humana em uma só tribo mundial” (LETONTURIER, Éric. Fiche de Lecture. Paris: Encyclopaedia Universalis France S.A., 2013. p. 80).

22 BAUMAN, Zygmunt; MAY, Tim. Aprendendo a pensar com a sociologia. Trad.: Alexandre Werneck. Rio de Janeiro: Zahar, 2010. p. 17. 
“rede de relação social”. ${ }^{23} \mathrm{O}$ crescimento das redes sociais, propulsado pela franca aceleração da comunicação, por meio da tecnologia da informação, acaba por trazer efeitos diretos sobre as pessoas, modificando o seu sentido de "espacialidade dos locais” e, por conseguinte, seus hábitos e comportamentos. ${ }^{24}$ A própria ideia de distância, "de afastamento ou proximidade", ${ }^{25}$ leva em conta o tempo, quanto ao número de horas, minutos, ou mesmo, segundos para alcançar.

É o que se depreende das lições de Lorenzetti: ${ }^{26}$

O surgimento da era digital suscitou a necessidade de repensar importantes aspectos relativos à organização social, à democracia, à tecnologia, à privacidade e à liberdade. O caráter aberto, interativo e global da internet, somado aos baixos custos da transação que apresenta como tecnologia, produzem um grande impacto em uma ampla categoria de questões pertencentes à sociologia jurídica e, logo, na dogmática: a noção de tempo, espaço, fronteira estatal, lugar, privacidade, bens públicos e outras que aparecem igualmente afetadas.

Portanto, sobretudo a noção de tempo, de espaço e, principalmente, de privacidade, deve ser objeto de cuidadosa apreciação pelos que se dedicam ao estudo do Direito.

Na sociedade digital, a informação move-se independente dos corpos físicos, permitindo que grupos de pessoas se comuniquem, vencendo a distância geográfica. ${ }^{27} \mathrm{~A}$ velocidade da comunicação dá-se no tempo de transmissão dos sinais eletrônicos. ${ }^{28} \mathrm{~A}$ "Word Wide Web" acaba por se tornar uma nova forma de "trofolaxe humana”, fazendo com que o consumidor seja proativo, produzindo e consumindo a comunicação. ${ }^{29}$

As atividades que ocorriam tão somente fisicamente passam a ser eletrônicas: surge a comunicação por e-mail, bem como o Facebook, substituindo o correio convencional; o Skype, como

23 Ibidem, p. 26.

24 Ibidem.

25 Ibidem, p. 176.

26 LORENZETTI, Ricardo Luis. Teoria da decisão judicial: fundamentos de direito. Trad.: Bruno Miragem. São Paulo: Revista dos Tribunais, 2010.

27 BAUMAN, op. cit.

28 Ibidem.

29 AZAMBUJA, Celso Candido de. Psiquismo Digital: Sociedade, cultura e subjetividade na era da comunicação digital. Nova Petrópolis: Editora Nova Harmonia, 2012. 
sucedâneo das reuniões e dos encontros presenciais; e, ainda, a "cloud computing”, para armazenamento de informações (imagens, fotografias, documentos, músicas, etc.), otimizando o arquivamento de dados, a saber:

Many of the activities that once occurred solely in the physical world, including communications with one another, are increasingly moving to the digital world. What was once a letter to a friend is now a Facebook message a call to a loved one is now a Skype chat; a private meeting with a business partner is now a video conference call. In short, the cloud is revolutionizing not only how we compute, but also how we live. Where individuals once locked personal or business papers solely in a desk drawer or filing cabinet, they now also store them on someone else's computer. ${ }^{30}$

É o que leciona Edwards e Waelde, ${ }^{31}$ identificando o crescimento do meio digital: "The enormous success of eBay, Facebook, Google, Second Life or Amazon illustrates how consumers and businesses alike have em- braced electronic commerce and the Internet in the last decade".

Crítica bastante pertinente é que novas habilidades, com novas ferramentas, acabam por afastar as antigas habilidades, e, se por um lado, é possível realizar as tarefas com mais rapidez (ou autonomia), por outro, acaba por aumentar a dependência do ser humano às novas tecnologias. ${ }^{32}$

Importante destacar que, nos primeiros anos da internet, parte considerável dos operadores do Direito eram defensores de um ambiente livre de regulação, sem leis, como noticia Edwards e Waelde: ${ }^{33}$

The early years of the Internet saw, on the part of some advocates at least, a brave vision of cyberspace as a lawless anarchic frontier free of the deadening hand of the lawyer and the industry monopolist, in no need of the laws and regulations that tie us down in the physical world.

Assim, identifica Lorenzetti, ${ }^{34}$ ao tratar acerca do caráter refratário do ciberespaço às regras legais:

30 THOMPSON, Richard. M. Cloud Computing: Constitutional and Statutory Privacy Protections. Washington: Congressional Research Service, 2013. p. 5.

31 EDWARDS, Lilian; WAELDE, Charlotte. Law and Internet. Oxford: Hart Publishing, 2010. p. 89.

32 BAUMAN, Zygmunt; MAY, Tim. Aprendendo a pensar com a sociologia. Trad.: Alexandre Werneck. Rio de Janeiro: Zahar, 2010.

33 EDWARDS, op. cit., p. 4.

34 LORENZETTI, Ricardo Luis. Teoria da decisão judicial: fundamentos de direito. Trad.: Bruno Miragem. São Paulo: Revista dos Tribunais, 2010. p.50. 
Existe um novo espaço: o cibernético (ciberespaço), diferente do espaço físico, com uma arquitetura caracterizada por sua maleabilidade, posto que qualquer um pode redefinir códigos e interagir neste espaço, o que converte em um objeto refratário às regras legais, as quais levam em conta tais elementos para decidir numerosos aspectos jurídicos.

Todavia, neste novo cenário apresentado pela sociedade digital, sensível ao operador do direito no que concerne ao estudo da sociologia, é que se observa um campo de conflitos normativos, inclusive, muitas vezes, de autonomia, devendo-se questionar acerca de sua regulação ou de livre atuação.

\subsection{Da era da desordem}

Ulpiano estabelecia fronteiras bastante delimitadas entre o campo do Direito Público e o do Direito Privado, conforme a intitulada Teoria dos Interesses. Nesta linha, quando a finalidade interessava ao Estado, tratava- -se de Direito Público, por outro lado, ao se voltar a interesses individuais, tratava-se de Direito Privado. ${ }^{35}$ Conforme os ensinamentos de Silva: ${ }^{36}$

[...] o Direito Constitucional e o Direito Privado eram considerados territórios autônomos, incomunicáveis, consequência natural da separação nítida entre o Estado e a sociedade, própria à concepção liberal então dominante; por outro lado, porque vigorava uma neutralidade valorativa que definia o Direito Privado.

Ao utilizar o Código Civil, fechava-se a Constituição, e vice-versa. Tratava-se do denominado "mono-sistema". ${ }^{37}$

Lorenzetti ${ }^{38}$ intitulou o momento histórico supramencionado, como a “era da ordem”, a saber:

Já houve uma "era da ordem", na qual o âmbito do direito público estava perfeitamente diferenciado do âmbito do direito privado, de tal modo que podia ser desenvolvida uma dogmática baseada em ambas as esferas

35 "Ius publicum, dizia Ulpiano (D.I,1,1,2), est quod ad statum rei Romanae spectat, priuatum quod ad singulorum utilitatem" (direito público é o que diz respeito ao interesse do Estado Romano; direito privado o que se refere ao interesse dos particulares" (ALVES, José Carlos Moreira. Direito romano. 14. ed. Rio de Janeiro: Forense, 2008. p. 85).

36 SILVA, Clóvis Veríssimo do Couto e; FRADERA, Vera Maria Jacob de. (org.). $O$ direito privado brasileiro na visão de Clóvis do Couto e Silva. Porto Alegre: Livraria do Advogado, 1997. p. 21.

37 IRTI, Natalino. L'età della decodificazione. Milano: Giuffrè, 1999.

38 LORENZETTI, op. cit., p. 39. 
independentes. As fontes eram autônomas e únicas: o direito público era tratado na Constituição, e o direito privado nos Código Civil e Comercial. As esferas de ambos continham pressupostos claros e princípios autônomos e tinham autossuficiência, de modo que não precisavam uma da outra.

Por outro lado, prosseguiu o mesmo autor, na atualidade estabeleceu-se a "era da desordem", ${ }^{39}$ uma vez que cada vez mais o direito público dialoga com o direito privado, por sua constitucionalização, assomado à descodificação, inclusive, por meio do que intitulou de "big bang legislativo", com a implosão da visão totalizante do Código Civil. ${ }^{40}$ De tal arte, opera-se a criação de microssistemas, a saber:

O Código, concebido como totalidade, enfrenta o surgimento dos microssistemas, caracterizados por normas com grande grau de autonomia, já que apresentam fontes próprias, leis, regulamentos, interpretação, congressos científicos, com uma especificidade que se acentua até se constituírem como subsistemas regulados. ${ }^{41}$
Importa destacar que novos fatos jurídicos merecem novas soluções jurídicas, não podendo ser resolvidas a partir das receitas já conhecidas, segundo leciona Rodotà: ${ }^{42}$ "L'intreccio tra innovazione tecnologica, mutamento sociale e soluzioni giuridiche pone ogni giorno problemi di fronte ai quali spesso appaiono del tutto improponibili i vecchi criteri, le ricette conosciute".

Para que as inovações legislativas sejam implementadas, haverão de se observar características próprias desta sociedade digital, reconhecendo suas peculiaridades que apontam para a criação de um microssistema próprio. É o que Lorenzetti ${ }^{43}$ aponta:

Há certo consenso de que existe crise das visões totalizadoras, e que o fenômeno do multiculturalismo é inegável. No plano jurídico surgem interesses individuais que entram em conflito horizontal de grande complexidade, na medida em que fazem explodir todo o texto unificador. $\mathrm{O}$ legislador enfrenta problemas para manter o caráter "geral", que é próprio da lei, já que em muitos temas sensíveis teria de fazer uma lei para cada um dos indivíduos que postu-

39 LORENZETTI, Ricardo Luis. Teoria da decisão judicial: fundamentos de direito. Trad.: Bruno Miragem. São Paulo: Revista dos Tribunais, 2010. p. 39.

40 Ibidem.

41 Ibidem, p. 44.

42 RODOTÀ, Stefano. Tecnologie e diritti. Bologna: Il Mulino, 1995. p. 9.

43 LORENZETTI, op. cit., p. 53. 
la seus interesses. No plano setorial acontece algo similar: o problema das denominadas "leis promocionais", que subsidiam alguma atividade específica, produziu uma fragmentação de direitos e privilégios que, por sua vez, provoca novas pressões setoriais para alcançar equiparação com o obtido por outro grupo ou superá-lo.

\section{Completa o mesmo autor:}

É um espaço do anonimato, um não lugar, pela despersonalização que apresenta, em que o indivíduo ingressa sem que sua história individual interesse suas características, e onde prolifera o simulacro das identidades. É um "não lugar global”, no sentido da transnacionalidade e atemporalidade, já que parecem indiferentes à história e ao futuro. [...] É um espaço com todas as características da pós-modernidade, e fraturado em múltiplos territórios caracterizados pela diferença: clubes, grupos, subgrupos, reunidos em torno de todo tipo de interesse hiperespecializado; domínios, subdomínios, nacionais, educativos ou comerciais. Parece, pois, não ter a característica essencial para se definir como tal; na tradição se estende o espaço como "continente de todos os objetos sensíveis que existem", mas no caso da internet não há continente nem objetos sensíveis. ${ }^{44}$
Ademais, valores constitucionais devem permear a análise da sociedade digital, conforme Marques, ${ }^{45}$ que assim se refere à teoria de Erik Jayme, demonstrando o liame entre o Direito Público e o Direito Privado:

O Leitmotive, elemento guia da teoria de Erik Jayme são os direitos humanos, como novos e únicos valores seguros a utilizar neste caso legislativo e desregulador, de codificações e microssistemas, de leis especiais privilegiadoras e de leis gerais imovíveis, de soft law e da procura de uma equidade cada vez mais discursiva do que é real. Os direitos humanos seriam as "normas fundamentais" e estes direitos, incluídos na Constituição, influenciariam o novo direito privado, a ponto do direito assumir um novo papel social, como limite da intervenção do Estado, como protetor do indivíduo e como inibidores de abusos, mas também como incentivador de uma ação afirmativa do Estado para alcançar a equidade e a igualdade material entre todas as pessoas na nova sociedade multicultural.

Nessa linha, Rodotà ${ }^{46}$ reconhece que, nesta seara, a intervenção do Estado deve proteger a privacidade das pessoas, à luz do princípio da

44 LORENZETTI, Ricardo Luis. Teoria da decisão judicial: fundamentos de direito. Trad.: Bruno Miragem. São Paulo: Revista dos Tribunais, 2010. p. 51.

45 MARQUES, Laudatio. Para Erik Jayme: memórias e utopia. Cadernos do Programa de Pós-Graduação em Direito, Porto Alegre, v. 1, n. 1, mar. 2003. p. 61.

46 RODOTÀ, Stefano. Tecnologie e diritti. Bologna: Il Mulino, 1995. p. 111-113. 
dignidade da pessoa humana e do direito de privacidade:

L'alternativa, a questo punto, è quella bem nota tra accetazione incondizionata della logica del mercato e creazione di un quadro istituzionale caratterizzato anche della imposizione di forme di tutela delle informazioni personali; tra diritto alla privacy come vincolo al gioco spontanteo delle forze e diritto alla privacy como mera attribuzione di titoli di proprietà liberamente negoziabili sul mercato; tra situazioni di inalienabilità dei diritti individuali e possibilità di disporre di tali diritto attraverso il consenso informato. [...] Qui non si tratta di respingere 'il paternalismo' del legislatore, invocando la libertà di scelta di ciascuno: si trata, allo stesso tempo, di registrare realisticamente i limiti del consenso individuale, inevitabili quando si è in presenza di forti disvelli di potere nelle relazioni di mercato, e di determinare gli standard minimi per la protezione effettiva di diritti fondamentali.

Importa destacar, ainda, que assim leciona Limberger: ${ }^{47}$

Pode-se concluir que a tutela dos direitos da pessoa deve ser compatibilizada com as exigências do mundo atual, que almeja a liberdade de informação e a livre circulação dos da- dos. Em última análise, a informática é algo que já se incorporou na vida quotidiana moderna. Hoje, não se vislumbra retrocesso. O desafio é como proteger os dados informatizados frente a uma sociedade e um mercado cada vez mais livres de fronteiras. A globalização pressupõe e propõe uma economia sem fronteira e sem regulamentação. No entanto, não se pode desprezar anos de construção de direitos fundamentais e mudar isso por uma única lei, a lei de mercado, e a ilusão que o mercado tudo regulará.

Nesse sentido, a dignidade da pessoa humana e os direitos de personalidade devem ser sopesados na construção e aplicação de regras que tratem acerca da sociedade digital.

\section{NOVOS RUMOS DO DIREITO SUCESSÓRIO NA ERA DIGITAL}

\subsection{Da história do Direito das Sucessões}

Se a sociedade evoluiu da comunicação fundada na oralidade para a era digital, de igual forma também há que se tecer novos rumos ao direito sucessório. Na antiguidade clássica, os gregos identificavam a morte como

47 LIMBERGER, Têmis. Direito e informática: o desafio de proteger os direitos do cidadão. In: SARLET, Ingo Wolfgang. Direitos Fundamentais, Informática e Comunicação. Porto Alegre: Livraria do Advogado, 2007. p. 225. 
uma mera mudança da existência, uma nova condição, inclusive roupas, armamentos e vasos eram deixados nos túmulos. ${ }^{48}$ As oferendas afastavam o morto da fome perpétua. ${ }^{49} \mathrm{~A}$ sucessão tinha como finalidade a continuação do culto, a partir da hereditariedade, em que o sucessor passa a ter a administração dos bens que eram de seu pai. De igual forma, os romanos compreendiam que o sucessor era o "continuador da própria pessoa do falecido", ${ }^{50}$ passando a tomar o "lugar do causante". ${ }^{51}$ Scialoja ${ }^{52}$ lecionou que a morte do pater tornava o grupo acéfalo, figurando o seu herdeiro na direção familiar, administrando "ele- mentos ativos e passivos de seu patrimônio". Ademais, três eram as funções da sucessão: não permitir que os credores do morto vendessem o seu patrimônio para saldar as dívidas, o que geraria difamação à memória do falecido; o continuador da sucessão era um novo devedor; teria a função de sacerdote da religião familiar. ${ }^{53}$ Entre os teutões, os bens deveriam permanecer em condomínio, ${ }^{54}$ servindo à comunidade familiar. ${ }^{55} \mathrm{O}$ povo germânico primitivo não elaborou uma "ideia endogênica de transmissão de bens". ${ }^{56}$

No Direito Medieval, a sucessão significava a continuidade do feudo,

48 COUlAngES, Numa Denis Fustel de. Cité antique. p. 8-10. Disponível em: $<$ http://www.dominiopublico.gov.br/download/texto/ga000425.pdf $>$. Acesso em: 10 jun. 2013.

49 Ibidem.

50 PETIT, Eugène. Traité élémentaire de droit romaine. Paris: Rosseau, 1925. p. 560561.

51 KASER, Max. Direito privado romano. Lisboa: Calouste, 1999. p. 365.

52 SCIALOJA, Vittorio. Diritto ereditario romano: concetti fondamentali. Padova: CEDAM, 1934. p. 7.

53 “Quand un chef de famille mourait, il était donc essentiel que ses sacra privata ne fussent pas interrompu. Pour en assurer la perpétuité, les pontifes avaient décidé que l’héritier aurait, avec la fortune du défunt, la charge du culte privé” (PETIT, Eugène. Traité élémentaire de droit romaine. Paris: Rosseau, 1925. p. 540).

54 MAZEAUD, Henri; MAZEAUD, Léon. Leçons de droit civil: successions - libéralités. v. 4. Paris: Montchrestien, 1999.

55 SILVA, João Gomes da. Herança e sucessão por Morte. Lisboa: Universidade Católica Editora, 2002.

56 NONATO, Orosimbo. Estudos sobre sucessão testamentária. Rio de Janeiro: Forense, 1957. p. 77. 
com base na masculinidade e na progenitura do filho. ${ }^{57} \mathrm{O}$ feudo era indivisível, dada a sua função militarizada. ${ }^{58}$ A sucessão, portanto, tinha como fundamento a família e a propriedade. $\mathrm{Na}$ Revolução Francesa, os privilégios da primogenitura e da masculinidade cessaram. ${ }^{59}$ Dessa forma, estabeleceu-se tratamento igualitário entre os herdeiros. ${ }^{60}$ Com o Código Civil Napoleônico, preservou-se o princípio da igualdade entre os filhos, no entanto, ressalvas aos filhos adulterinos. ${ }^{61}$
Em Portugal, buscava-se manter os bens na família, a partir do conceito de troncalidade, estabelecendo uma reserva sucessória. ${ }^{62}$ Havia ainda o regime dos morgados, quanto aos bens da Coroa Portuguesa, no sistema de manutenção da unidade da casa familiar. ${ }^{63}$ Com o Código Civil Português de 1867, a partir da solidariedade familiar, houve o reconhecimento do direito de suceder, estendido aos filhos naturais. ${ }^{64} \mathrm{O}$ vigente direito sucessório português, a partir

57 MAZEAUD, op. cit.

58 GILISSEN, John. Introdução histórica ao direito. Trad.: A. M. Hespanha. Lisboa: Calouste, 1995.

59 SAVATIER, René. Cours de Droit Civil. Paris: Librairie Generale de Droit e de Jurisprudence, 1951.

60 "Enfin, elle superposa à ces directrices une véritable mystique égalitaire, obligeant, dans tous le cas, le père ou la mère à ne faire, dans l'attribution de leur succession, aucune différence entre leurs enfant legitimes, et même naturels, si du moins, la filiation de ces derniers était régulièrement prouvée” (Ibidem, p. 196).

61 Ibidem.

62 Ibidem.

63 Ibidem.

64 A saber: “O phenomemo natural da procreação já nos vimos, que originava a família natural, porque também é fonte das relações necessarias de mutua condicionalidade entre procreador e procreado. Na hypothese, portanto, em que procedencia dos filhos naturaes ou legitimos é egualmente consanguinea e uterina, o facto da procreação é comum a todos e identico na pessoa do procreador. Logo, com relação a este, uns e outros filhos pertencem á mesma familia natural: logo devem succeder egualmente nos bens do procreador comum" (CALLISTO, Avelino Cesar Augusto Maria. Os filhos naturaes, legalmente perfilhados ou reconhecidos, antes ou depois do matrimonio, devem ter uma legitima egual á dos filhos legitimos, de qualquer dos paes perfilhantes. Coimbra: Imprensa da Universidade de Coimbra, 1871. p. 33-35. Disponível em: <http://www. fd.unl.pt/Anexos/Investigacao/1201.pdf>. Acesso em: 10 jul. 2013). 
de uma codificação de 1966, à luz da Constituição Portuguesa, de 1976, ${ }^{65}$ passou a tratar de forma igualitária os seus filhos, havidos ou não dentro do casamento. ${ }^{66}$

No Brasil, a legislação precodicista refletia a legislação reinícola das ordenações e dos alvarás, que refletia uma visão patrimonialista. Com o advento do Código Civil de 1916, estabeleceu-se um diploma com base na sociedade patriarcal:

A despeito de sua ilustração, a aristocracia de anel representava e racionalizava os interesses básicos de uma sociedade ainda patriarcal, que não perdera o seu teor privatista, nem se libertara da estreiteza do arcabouço econômico. ${ }^{67}$

Sendo assim, Gomes ${ }^{68}$ referiu que:

No campo do direito hereditário, a preocupação pela estabilidade do grupo familiar ostenta-se em traços berrantes. Para facilitar a conservação do patrimônio formado pelo chefe de família e atender à preocupação, muito difundida, de garantir o futuro dos filhos, preservando-os da adversidade ou prevenindo-lhes a estroinice, permite a substituição fideicomissária, considerada obsoleta já naquele tempo, e confere ao testador o direito incondicionado de gravar os bens dos herdeiros, mesmo os que constituem a legítima, com a cláusula de inalienabilidade vitalícia.

A partir deste escorço histórico é que se pôde verificar que o direito sucessório refletiu os valores implementados para cada época, em que a terra, o patrimônio, era o centro. Contudo, não se pode julgar os momentos históricos passados com os olhos do presente sem sopesar a sua situação social peculiar, sob pena de pecar pelo anacronismo. Pois então, questiona-se: Como deve ser a construção do direito sucessório diante da sociedade digital?

\subsection{Novos rumos do Direito das Sucessões frente à sociedade digital}

Segundo Lorenzetti, ${ }^{69}$ tem-se que "todos os campos do Direito Priva-

65 TELLES, Inocêncio Galvão. Direito das sucessões. Coimbra: Coimbra, 1996.

66 VARELA, João de Matos Antunes; LIMA, Fernando Andrade Pires de. Código civil anotado. Coimbra: Coimbra, 2010. v. 5.

67 GOMES, Orlando. Direito Privado (Novos Aspectos). Rio de Janeiro: Freitas Bastos, 1961. p. 94.

68 Ibidem, p. 89.

69 LORENZETTI, Ricardo Luis. Fundamentos do direito privado. São Paulo: Revista dos Tribunais, 1998. p. 254. 
do" devem guardar uma "perspectiva constitucional", ${ }^{70}$ tendo a Constituição como o "Sol" e centro do "novo sistema solar". ${ }^{71}$

Nesse sentido, a sucessão também deve estar sob o amparo do princípio da dignidade da pessoa humana, bem como da solidariedade social, nos veios dos artigos $1^{\circ}$, III, e $3^{\circ}$, I da Constituição Federal, voltando-se a uma visão existencialista. Tepedino ${ }^{72}$ aponta esta evolução no direito sucessório do patrimonialista para os valores socialmente relevantes:

Por fim, a forma dos atos jurídicos que se voltava no passado exclusivamente para a segurança patrimonial, no sentido de proteger as transferências patrimoniais inter vivos e causa mortis, especialmente no que tange aos bens imóveis, passa a exercer papel limitador da autonomia privada em favor de interesses socialmente relevantes e das pessoas em situação de vulnerabilidade. $^{73}$
Portanto, o direito sucessório, na era digital, deve ser visto sob uma visão “constitucionalizada” e "despatrimonializada". ${ }^{74}$ Os bens, atualmente, não são tão somente físicos, pois: a) nas nuvens, estão armazenados inúmeros dados (profissionais, pessoais, obras intelectuais), com conteúdo patrimonial ou extrapatrimonial $;^{75}$ b) nos e-mails, informações sigilosas, de hábitos e costumes, sexuais, de saúde, envolvendo, inclusive, terceiros; c) no Facebook, não é incomum identificar perfis de pessoas mortas, que mesmo passados anos, seus dados são de possível acesso.

Assim, o que fazer quando os usuários morrem? Como lidar com o direito de personalidade e de privacidade? Até que ponto a constitucionalização irá pautar este tratamento legislativo?

A resposta poderia ser simples: se o falecido deixou a senha tudo certo,

70 Ibidem, p. 252.

71 Ibidem, p. 145.

72 TEPEDINO, Gustavo. Temas de direito civil. v. 3. Rio de Janeiro: Renovar, 2009. p. 14.

73 Idem, p. 15.

74 Ibidem.

75 "Cloud computing is fast becoming an integral part of how we communicate with one another, buy music, share photos, conduct business, pay our bills, shop, and bank.” (THOMPSON, Richard. M. Cloud Computing: Constitutional and Statutory Privacy Protections. Washington: Congressional Research Service, 2013. p. 4). 
acesso irrestrito, caso contrário, não. Este raciocínio não é cabível, pois nem todas as pessoas deixam a chave de seus apartamentos ou cofres, e, contudo, não há qualquer dúvida no que toca ao acesso de seus familiares.

Não há dúvida que se verifica uma imensa dificuldade em tratar acerca da morte, o que também se verifica na relação da tecnologia, como ensina Seminerio: ${ }^{76}$

A finitude é uma realidade, é nossa própria realidade como seres humanos, como seres existentes, porque tudo o que existe apresenta esta condição. No entanto, no ser humano há um conflito permanente, que é a tentativa contínua em todo os seus atos de a ultrapassar, de a transcender. Deste conflito resultam dois aspectos também contraditórios e conflitantes: por um lado, um desejo à ação, à realização - é aquilo que cria a história e a cultura, e, por outro, uma sensação de desespero, de desânimo ao verificar os limites que lhe são impostos.

O que na verdade há que ser desenvolvida é uma cultura que enfrente a morte, na área da tecnologia, criando setores ou formulários em que o usuário possa dar o adequado destino aos seus dados.

Nesse sentido, há que se ponderar a necessidade da regulação legislativa, visto que os serviços informáticos estão marcados pela disparidade de poderes, no confronto entre o fornecedor e o consumidor, como leciona Rodotà, ${ }^{77}$ a saber:

Si può aggiungere più in generale, che l'utente di servizi informatici e telematici si trova in una situazione di marcata disparità di potere nei confronti del fornitore di tali servizi, così che non si può a rigore parlare di un consenso liberamente manifestato per le transazioni riguardanti la privacy.

Rodotà $^{78}$ acentua quatro tendências para os dados, desde a liberdade ao controle total:

L'ambiente nel quale opera la nozione di privacy viene così ad essere caratterizzato dai tre paradossi già enunciati e da quatro tendenze che possono essere così sintetizzare: 1) dal diritto d'esser lasciato solo al diritto di mantenere il controllo sulle informazioni che mi riguardano; 2) dalla privacy al diritto all'autodeterminazione

76 SEMINERIO, Franco Lo Presti. Existência e Finitude. In: PY, Ligia (org.). Finitude para uma proposta para reflexão e prática em gerantologia. Rio de Janeiro: Nau Editora, 1999. p. 9; 21-30.

77 RODOTÀ, Stefano. Tecnologie e diritti. Bologna: Il Mulino, 1995. p. 55.

78 Ibidem, p. 108. 
informativa; 3) dalla privacy alla non discriminazione; 4) dalla segretezza al controlo.

Assim, o direito de intimidade/ privacidade, a privacy, deve ser reconhecido como um direito fundamental, acompanhado de um regime de exceções. ${ }^{79}$ Afastando-se de uma visão eminentemente utilitarista. ${ }^{80}$

Sob este ponto de vista, no que toca às "cloud computing”, ou seja, às nuvens que armazenam dados, incumbe destacar que se poderia estabelecer diferentes grupos de dados, incluindo desde setores personalíssimos, em que seria imediatamente destruído, quando da morte do usuário, bem como setores de informações profissionais, intelectuais, cujo acesso seria franqueado aos seus sucessores, inclusive visto terem repercussões econômicas. O que não poderia acontecer é ver o direito de privacidade violado, tendo como argumento único o econômico. Isto representaria a contramão da história até então desenvolvida.
De tal arte, o usuário, como condição para utilização desses recursos, já se manifestaria acerca de suas opções, sendo aplicada uma regra padrão em caso de silêncio.

O mesmo quanto aos e-mails, visto que seria possível criar caixas acessíveis e inacessíveis aos seus sucessores.

No que toca ao Facebook, já há um formulário próprio acerca da temática, para que familiares avisem da morte, transformem o perfil em um memorial, bem como serviços como "If I die”, que se aplica a situações em que as pessoas, em falecendo, deixam mensagem aos seus amigos. ${ }^{81}$

Enfim, há muito que se desenvolver.

\section{CONSIDERAÇÕES FINAIS}

A partir do estudo realizado, tornou-se possível tecer as seguintes considerações finais:

A uma, identifica-se, no transcurso histórico, a evolução da comunicação da linguagem oral para a linguagem escrita, até atingir o digital;

79 Ibidem.

80 "Críticos do utilitarismo apontam esses episódios como provas de que a análise de custo e benefício leva a enganos e que atribuir um valor monetário à vida humana é moralmente errôneo" (SANDEL, Michael J. Justiça: o que é fazer a coisa certa. Rio de Janeiro: Civilização Brasileira, 2012. p. 59).

81 SAIBA como desativar perfil de usuário do Facebook que morreu. G1 on line. 25 abr. 2013. Disponível em: <http:/g1.globo.com/tecnologia/noticia/2013/04/saiba-como-desativar-perfil-de-usuario-do-facebook-que-morreu.html>. Acesso em: 24 jul. 2013. 
A duas, estabeleceu-se uma sociedade digital, com novos desafios, que destoam do tradicional tratamento legislativo, sobretudo no que tange ao tempo e ao espaço;

A três, o direito das sucessões deve acompanhar a evolução digital, buscando dar-lhe adequado tratamento;

A quatro, o direito das sucessões deve, à luz da ordem constitucional,

\section{REFERÊNCIAS}

ALVES, José Carlos Moreira. Direito romano. 14. ed. Rio de Janeiro: Forense, 2008.

ARAÚJO, Inês Lacerda. Formação discursiva como conceito-chave para a arqueogenealogia de Foucault. Revista Aulas, Campinas, n. 3, p. 1-24, dez. 2006/mar. 2007.

AZAMBUJA, Celso Candido de. Psiquismo Digital Sociedade, cultura e subjetividade na era da comunicação digital. Nova Petrópolis: Nova Harmonia, 2012. BAUMAN, Zygmunt; MAY, Tim. Aprendendo a pensar com a sociologia. Trad.: Alexandre Werneck. Rio de Janeiro: Zahar, 2010.

CALLISTO, Avelino Cesar Augusto Maria. Os filhos naturaes, legalmente perfilhados ou reconhecidos, antes ou depois do matrimonio, devem ter uma legítima egual determinar a regulamentação no mundo digital, sobretudo, atenta ao direito de personalidade e "privacy";

A cinco, para cada ferramenta tecnológica deve o legislador dar o seu enfrentamento, respeitando as suas peculiaridades, criando setorizações de informações;

A seis, deve o mundo digital, tão avançado, estar sensível à relação entre a tecnologia e à morte.

á dos filhos legitimos, de qualquer dos paes perfilhantes. Coimbra: Imprensa da Universidade de Coimbra, 1871. p. 33-35. Disponível em: <http://www.fd.unl.pt/ Anexos/Investigacao/1201.pdf $>$. Acesso em: 10 jul. 2013.

COULANGES, Numa Denis Fustel de. Cité antique. p. 8-10. Disponível em: <http:// www.dominiopublico.gov.br/ download/texto/ga000425.pdf>. Acesso em: 10 jun. 2013.

EDWARDS, Lilian; WAELDE, Charlotte. Law and Internet. Oxford: Hart Publishing, 2010. FOUCAULT, Michel. A ordem do discurso: aula inaugural no Collège de France, pronunciada em dezembro de 1970. Trad.: Laura Fraga de Almeida Sampaio. São Paulo: Edições Loyola, 2012. 
GILISSEN, John. Introdução histórica ao direito. Trad.: A. M. Hespanha. Lisboa: Calouste, 1995.

GOMES, Orlando. Direito Privado (Novos Aspectos). Rio de Janeiro: Freitas Bastos, 1961.

GROSSI, Paolo. Mitologias Jurídicas da Modernidade. Florianópolis: Boiteux, 2007.

IRTI, Natalino. L'età della decodificazione. Milano: Giuffrè, 1999.

KASER. Max. Direito privado romano. Lisboa: Calouste, 1999.

LETONTURIER, Éric. Fiche de Lecture. Paris: Encyclopaedia Universalis France S.A., 2013.

LIMBERGER, Têmis. Direito e informática: o desafio de proteger os direitos do cidadão. In: SARLET, Ingo Wolfgang. Direitos Fundamentais, Informática e Comunicação. Porto Alegre: Livraria do Advogado, 2007.

LORENZETTI, Ricardo Luis. Fundamentos do direito privado. São Paulo: Revista dos Tribunais, 1998. Teoria da decisão judicial: fundamentos de direito. Trad.: Bruno Miragem. São Paulo: Revista dos Tribunais, 2010.

MACLUHAN, Marshall. The Gutenberg Galaxy. The making of Typographic Man. Toronto: Toronto University Press, 2011.

MARQUES, Laudatio. Para Erik Jayme: memórias e utopia. Cadernos do Programa de Pós-Graduação em Direito, Porto Alegre, v. 1, n. 1, mar. 2003.
MAZEAUD, Henri; MAZEAUD, Léon. Leçons de droit civil: successions - libéralités. Paris: Montchrestien, 1999. v. 4.

NONATO, Orosimbo. Estudos sobre sucessão testamentária. Rio de Janeiro: Forense, 1957.

PETIT, Eugène. Traité élémentaire de droit romaine. Paris: Rosseau, 1925.

RODOTÀ, Stefano. Tecnologie $e$ diritti. Bologna: Il Mulino, 1995.

SAIBA como desativar perfil de usuário do Facebook que morreu. G1 on line. 25 abr. 2013. Disponível em: <http://g1.globo.com/ tecnologia/noticia/2013/04/saibacomo-desativar-perfil-de-usuariodo-facebook-que-morreu.html>. Acesso em: 24 jul. 2013.

SANDEL, Michael J. Justiça: o que é fazer a coisa certa. Rio de Janeiro: Civilização Brasileira, 2012.

SAVATIER, René. Cours de Droit Civil. Paris: Librairie Generale de Droit e de Jurisprudence, 1951.

SCIALOJA, Vittorio. Diritto ereditario romano: concetti fondamentali. Padova: CEDAM, 1934.

SEMINERIO, Franco Lo Presti. Existência e Finitude. In: PY, Ligia (org.). Finitude para uma proposta para reflexão e prática em gerantologia. Rio de Janeiro: Nau Editora, 1999. p. 21-30.

SILVA, Clóvis Veríssimo do Couto e.; FRADERA, Vera Maria Jacob de. (org.). O direito privado brasileiro na visão de Clóvis do Couto e Silva. Porto Alegre: Livraria do Advogado, 1997. 
SILVA, João Gomes da. Herança e sucessão por Morte. Lisboa: Universidade Católica Editora, 2002.

TELLES, Inocêncio Galvão. Direito das sucessões. Coimbra: Coimbra, 1996.

TEPEDINO, Gustavo. Temas de direito civil. v. 3. Rio de Janeiro: Renovar, 2009.
THOMPSON, Richard. M. Cloud Computing: Constitutional and Statutory Privacy Protections. Washington: Congressional Research Service, 2013.

VARELA, João de Matos Antunes; LIMA, Fernando Andrade Pires de. Código civil anotado. v. 5. Coimbra: Coimbra, 2010. 